\title{
APRESENTAÇÃO \\ O INSÓLITO FICCIONAL NA LITERATURA E NAS ARTES
}

As manifestações da arte surgem em tempos e espaços sempre determinados, marcados por características próprias e variadas, assim sendo, o olhar crítico e reflexivo a respeito da arte exige renovadas formas, conceitos, tipologias e teorias que devem diversificar-se no percurso espaçotemporal. A produção da arte e a sua recepção crítica podem conjugar-se e apontar dimensões valiosas para os estudos acadêmicos. Dessa forma, pensando que as mudanças de perspectiva em relação ao conceito de insólito ficcional estão intimamente associadas às produções literárias e artísticas formuladas em diferentes momentos históricos e culturais, foi proposto o dossiê "O insólito ficcional na literatura e nas artes" a fim de refletir sobre as diferentes expressões literárias e os instrumentais teórico-críticos utilizados para a compreensão das manifestações do insólito ficcional.

Partindo da ideia de que existe uma relação intrínseca e tensiva na aproximação dos conceitos de realidade e de insólito, das dimensões do real e do irreal, do possível e do impossível ou, ainda, nas separações entre o natural e o sobrenatural, identificam-se na literatura e nas artes variadas possibilidades de expressão dessas tensões e problematizações. Em cada época, o pensamento humano pode aceitar ocorrências naturais, sobrenaturais, estranhas, inexplicáveis e insólitas ou duvidar delas, e as dúvidas em relação a tais ocorrências correspondem à expectativa comum dos indivíduos que vivenciam uma determinada época, logo, na diversidade das expressões literárias, esse universo díspar se manifesta por meio de diferentes contornos estéticos.

Inúmeros são os teóricos e escritores que buscaram conceituar as narrativas que instrumentalizam o fantástico, ora em um 
sentido restrito, como um gênero literário que se diferencia dos demais, ora como um modo narrativo, tentando compreender de quais maneiras o insólito ficcional se constrói na trama narrativa. No âmbito de um macrogênero, os estudos atuais da literatura fantástica enfocam as manifestações dos eventos insólitos, ou seja,

[...] aqueles que não são frequentes de acontecer, são raros, pouco costumeiros, inabituais, não usuais, incomuns, anormais, que contrariam o uso, os costumes, as regras e as tradições, enfim, que surpreendem ou decepcionam o senso comum, as expectativas quotidianas (GARCíA, 2012, p. 36).

Assim, refletir sobre as variadas formas de expressão literária que se revestem com as tintas do insólito significa percorrer uma trajetória teórica ampla e profícua, que procura desvendar os sentidos das imagens insólitas, tradutoras da presença do impossível em um cotidiano aceito como real. Nesse sentido, os limites do mundo conhecido são rompidos ou fragilizados, e, como consequência, surgem os temores diante da ameaça, diante dos abalos que podem transformar a realidade, do pavor ante o desconhecido e incontrolável.

No que tange às primeiras reflexões teóricas sobre o fantástico, merecem destaque os estudos de Charles Nodier, as reflexões do escritor Guy de Maupassant, no final do século XIX, e as ideias de Pierre-Georges Castex, no início do século XX. Posteriormente, os estudos de Louis Vax, Roger Caillois, Tzevetan Todorov, Jean Bellemin-Noël e Irène Bessière colocam novos questionamentos em pauta sobre a narrativa fantástica, quanto às tipologias propostas para classificá-la como um gênero ou quanto à lógica narrativa que lhe é inerente, formal ou temática. Podemos considerar os estudos desses teóricos como textos fundadores, cujas ideias, topologias, conceitos e teorias serão retomados posteriormente nos estudos de Filipe Furtado, Remo Ceserani, David Roas, Rosalba Campra, entre outros.

Se, para Todorov, o fantástico faz fronteira com dois outros gêneros similares, o estranho e o maravilhoso, defini-lo significa enfatizar as diferenças importantes e decisivas que o separam dos gêneros vizinhos. As bases que fundamentam a teoria de Todorov (1975) em Introdução à literatura fantástica constituem um marco nos estudos teóricos que definem a perspectiva de fantástico entendido como um gênero literário. As reflexões que mobilizam o estudo e a leitura desse sentido do fantástico se ocuparam em propor uma definição teórica que estabelecia os limites do fantástico no marco de um 
entendimento genealógico; assim, no fantástico, entendido como gênero, são construídos os limites e os sentidos do que se definiu como gêneros vizinhos, a saber, o estranho e o maravilhoso (TODOROV, 1975). Os estudos de Todorov se mantêm presentes em diferentes estudos teóricos, seja por meio da contestação, seja por meio da revisão.

As manifestações das imagens insólitas na narrativa fantástica do século XIX têm como característica basilar a construção dos efeitos de ambiguidade. Sem ela, a narrativa deixa de ser considerada fantástica e passa a pertencer, segundo Todorov, a um outro gênero. O fantástico, postulado como gênero, fundamenta-se, a partir dos estudos de Todorov, na hesitação do narrador e do leitor, que não sabem como explicar de forma racional e lógica os acontecimentos que estão diante de seus olhos.

Entretanto, perante o grande número e a heterogeneidade de textos produzidos ao longo dos séculos, como pensar uma definição do fantástico contemporâneo? Para David Roas (2014), o que caracteriza o fantástico contemporâneo, das narrativas produzidas principalmente a partir do século XX, é a irrupção do anormal em um mundo aparentemente normal, não para demonstrar a evidência de algo sobrenatural, e sim para postular a possível anormalidade dentro da nossa realidade cotidiana. Logo, as formas de representar o real no âmbito da literatura não estão restritas tão somente às formulações realistas. O real que se expressa na escritura ficcional é capaz de propor enigmas perturbadores para o leitor, de problematizar a sua percepção do real, de levá-lo a imaginar o mundo que não é tangível, mas possível no contexto da diegese.

Para este dossiê, foram selecionados nove artigos que estudam os aspectos teóricos do fantástico, visto como gênero, e, também, as dimensões do insólito ficcional, entendido no âmbito de um macrogênero, observando suas diferentes manifestações, seja nos textos literários, pertencentes a diferentes períodos, seja nas diferentes formas de expressões artísticas.

Cada artigo traz uma contribuição particular em sua abordagem crítica, por enfocar textos de autores nacionais ou estrangeiros, produzidos em diferentes épocas e contextos. Artigos que nos permitem apreender, por exemplo, as diferenças entre o fantástico compreendido como gênero ou como modo narrativo, as perspectivas do insólito ficcional na narrativa contemporânea, bem como as nuances do real maravilhoso e do fantasy. Na diversidade dos estudos, observa-se uma linha que perpassa as análises: a reflexão sobre os 
sentidos do humano e do real, os dilemas humanos dispersos em mundos insólitos ou não.

A literatura portuguesa é contemplada no artigo "O insólito na narrativa-moldura de A lenda da meia-noite, de Pinheiro Chagas”. O articulista examina o efeito do fantástico e a irrupção do insólito nos cinco contos que compõem a coletânea. Em cada conto, emerge a voz de um interlocutor, que resgata um fato singular vivenciado no passado ou uma história que lhe foi contada por terceiros, como uma forma de entretenimento, uma vez que todos estão reunidos em uma casa antiga situada numa região rural de Portugal, cuja temporada de caça foi interrompida por dias chuvosos e frios. Cada um dos interlocutores compromete-se a contar uma história fantástica com o objetivo de amenizar o medo da meia-noite, devendo, contudo, privilegiar os espaços soturnos e os elementos fundamentais de uma narrativa fantástica, como fantasmas, espectros, seres sobrenaturais ou diabólicos. As narrativas encaixadas, que contribuem para a evolução da ação principal e compõem a narrativa-moldura da coletânea, são examinadas em uma relação intertextual com produções góticas, maravilhosas e fantásticas em que a estrutura de moldura também é empregada.

Sono, do escritor e tradutor japonês Haruki Murakami, foi publicado pela primeira vez em 1990, com belíssimas ilustrações de Kat Menschik. Utilizando-se de uma metodologia descritivo-analítica e embasada, principalmente, nos estudos de Remo Ceserani e Irène Bessière, a articulista, no texto "O insólito ficcional e o duplo em Sono, de Haruki Murakami”, objetiva examinar os procedimentos narrativos e os temas do fantástico na construção da trama narrativa. Partindo das considerações iniciais da narradora-personagem em relação ao seu cotidiano inalterável e de suas lembranças do passado, quando uma sonolência "parecida com insônia" a acometia uma vez por mês, a articulista analisa as mudanças de comportamento da narradora no momento presente, no qual ocorre a irrupção do insólito e do duplo com a materialização de duas sombras, durante contínuas noites de insônia. Passo a passo, a cada capítulo da narrativa, a autora do artigo busca explicitar como a narradora-protagonista age e reage dentro de dimensões diversas, e em que medida se instaura a desrazão que se alimenta das realia, da materialização de duplos antagônicos e de sua dupla imagem no espelho.

A questão do duplo é retomada no artigo "A femme fatale como duplo em Gastão Cruls”, que coloca em pauta a ficção brasileira decadentista, ainda 
pouco explorada pelos estudiosos. Partindo da hipótese do "fantástico decadentista" como um submodo específico do fantástico, a articulista examina os recursos da prosa de ficção decadentista utilizados por Gastão Cruls para criar narrativas fantásticas, analisando duas obras específicas: o romance Elza e Helena e o conto "O espelho". Nas duas narrativas, a imagem da femme fatale está associada à duplicidade das personagens mediadas por objetos: no romance, por um espelho e pela confecção de uma boneca costurada pela própria Elza à sua imagem; no conto, por um espelho tripartido, decorado com "figurinhas de sátiros e ninfas". O artigo traz uma contribuição importante para o estudo do caso clássico de Doppelgänger (tópos do espelho), na literatura brasileira decadentista.

O artigo "Mulheres insólitas: a presença do neofantástico no conto 'Pequeñas mujercitas', de Solange Rodríguez Pappe” tem por escopo analisar os mecanismos utilizados na construção da trama narrativa pertinentes ao fantástico contemporâneo e as questões sociais que emergem nas entrelinhas do texto, tais como: os valores patriarcais dominantes; a ruptura dos padrões sociais cristalizados; a conversão da mulher objeto em mulher sujeito; e, por fim, a normalização do elemento insólito. Para tanto, utilizando-se principalmente do conceito de neofantástico, proposto pelo argentino Jaime Alazraki, o articulista examina como a aceitação do insólito - ou seja, a sociedade das pequeñas mujercitas - vai se internalizando nas tramas do discurso, sem que haja um questionamento da narradora-personagem ou do leitor sobre os eventos incomuns ali inseridos. Nesse aspecto, a narrativa de Solange Rodríguez Pappe se diferencia da narrativa tradicional proposta por Todorov, pois a organização textual, a ambiguidade e a passividade diante de eventos incomuns correspondem a uma nova forma de lidar com o surgimento do insólito em um cenário pretensamente dentro da normalidade e de debater questões sociais.

As perspectivas teóricas do realismo maravilhoso são estudadas no artigo "Clara, a clarividente: o insólito ficcional na personagem”, a partir da análise da personagem Clara do romance $A$ casa dos espíritos, da escritora chilena Isabel Allende. Nas análises, os elementos insólitos são compreendidos em sua amplitude significativa, pois tanto são parte indissociável da personagem Clara, protagonista da narrativa, como estabelecem o encantamento imanente à composição do enredo. Observa-se que as perspectivas teóricas que marcam o realismo maravilhoso latino-americano são apresentadas nesse estudo a fim 
de estabelecer os preceitos de um desafio estético, pois a narrativa de Isabel Allende, que revela a realidade histórica do Chile e permite uma reflexão sobre os contornos da ditadura chilena e dos valores do patriarcado, constrói-se a partir de uma naturalização dos eventos insólitos, explicitada nas ações e nos acontecimentos que envolvem a personagem Clara.

O artigo "Lo neofantástico en Aura, de Carlos Fuentes: dimensiones espaciales y temporales en la construcción narrativa" propõe uma análise da novela Aura a partir dos limites teóricos do neofantástico, estabelecidos pelos estudos teóricos de Jaime Alazraki, em especial no ensaio “Qué es lo neofantástico?”. Nesse estudo, Alazraki assinala que a intenção da narrativa do neofantástico, diferentemente do fantástico, não é produzir o efeito do medo, mas sim provocar a perplexidade por meio da presença das imagens insólitas, e, dessa forma, o seu propósito seria expressar, pelas metáforas, certa percepção singular da realidade. O contexto do surgimento do conceito de neofantástico é desenvolvido a partir da ótica do crítico Rámon Xirau, que investiga as mudanças e renovações ocorridas na trajetória da literatura latino-americana. As dimensões do tempo e do espaço são importantes para a análise da obra Aura, pois se constituem como manifestações do insólito presentes na obra e, como tal, aparecem destacadas nesse estudo, na medida em que os sentidos da sobreposição temporal, a mistura do presente e do futuro ou do passado e do presente, passam a anunciar os traços de uma proposição narrativa neofantástica.

No artigo "Entre lo real y lo irreal, mundos (im)posibles. Lo fantástico presente en 'Verónica' y 'La extraña muerte de fray Pedro', de Rubén Darío”, são analisadas as duas versões de um conto de Rubén Darío sob a perspectiva do fantástico, entendido como gênero. O artigo destaca a forma de composição dos relatos fantásticos elaborados pelo escritor nicaraguense observando as rupturas das perspectivas estilísticas estabelecidas pelo modernismo hispano-americano e assinala, também, a presença de alguns aspectos que remetem ao mestre do fantástico, Edgar Allan Poe, investigando os cenários misteriosos, a gradação da tensão e a construção de desenlaces surpreendentes. $\mathrm{Na}$ análise proposta, evidenciam-se as convergências e divergências entre as versões dos contos de Rubén Darío, revelando as diferentes formas de manifestação do fantástico presente em ambas as versões.

No artigo "Nem mocho, nem cotovia", a partir dos preceitos teóricos de Todorov (2017) e Ceserani (2006), estuda-se o conto “A noite”, de Guy de Maupassant, a partir do desenvolvimento de uma análise dividida em três partes. 
Primeiramente, destacam-se as descrições da noite e a expressão do encantamento do narrador pela noite, logo, surgem a expressão do devaneio do narrador e a sua aparente confusão mental que condiz a uma transfiguração da noite, e, por fim, explora-se a recuperação da consciência por parte do narrador. A leitura do conto "A noite" permite uma reflexão a respeito das complexas estratégias de organização de uma narrativa, que se apresenta como um desafio para o leitor, e observa-se, ainda, a forma como Maupassant, um clássico da literatura, estabelece a fruição e o prazer estético. Nas entrelinhas da narrativa, revelam-se aspectos de uma polissemia discursiva e, também, as nuances de uma universalidade, elementos que favorecem a legitimidade e a permanência de uma obra.

No artigo "Fantasy: o herdeiro mainstream do fantástico-maravilhoso", que fecha este dossiê, discute-se como a literatura de fantasia, ou fantasy, constitui-se como um gênero literário que tem sua origem no fantástico tradicional e no maravilhoso, na definição clássica de Todorov na qual o maravilhoso é o fantástico aceito. $\mathrm{O}$ artigo desenvolve a ideia de que tanto o fantástico quanto a fantasia podem enfrentar alguma resistência do público leitor, por conta do insólito existente nas narrativas que obriga o leitor a romper com a realidade de alguma maneira. A fantasia apresenta uma complexidade causada pela necessidade de criar mundos complexos e exigir ainda mais suspensão da realidade, no entanto seus leitores e fãs entendem tais demandas como os principais atrativos das histórias e transformaram a fantasia em um fenômeno de público na atualidade.

O dossiê "O insólito ficcional na literatura e nas artes" teve como objetivo abrir um espaço propício para o intercâmbio de estudos críticos a respeito das diferentes vertentes do fantástico e das manifestações do insólito no âmbito da literatura e das artes. A leitura dos artigos aqui apresentados propicia uma oportunidade singular de conhecer os percursos teóricos que sustentam os limites do insólito ficcional e, também, de desvendar uma diversidade de escritores, que se aventuram a descrever os descaminhos dos mundos insólitos, na sua perspicaz sintonia com as muitas formas de experiências e desejos humanos.

ANA Lúcia Trevisan

Maria Luiza Guarnieri Atik 


\section{REFERÊNCIAS}

CESERANI, R. O fantástico. Coimbra: Editora UFPR, 2006.

GARCÍA, F. O “insólito” na narrativa ficcional: a questão e os conceitos na teoria dos gêneros literários. In: GARCÍA, F. (org.). A banalização do insólito: questões de gênero literário - mecanismos de construção narrativa. Rio de Janeiro: Dialogarts, 2007. p. 11-22. Disponível em: www.dialogarts.uerj.br. Acesso em: 6 abr. 2021.

ROAS, D. A ameaça do fantástico. Aproximações teóricas. São Paulo: Unesp, 2014.

TODOROV, T. Introdução à literatura fantástica. São Paulo: Perspectiva, 1975. 